\title{
The beauty of ant antics
}

\author{
Deborah M. Gordon enjoys a photographic paean to individual ants and their rarely glimpsed \\ exploits on behalf of the collective.
}

\author{
Adventures Among Ants: A Global Safari \\ with a Cast of Trillions \\ by Mark W. Moffett \\ University of California Press: 2010. 288 pp. \\ $\$ 29.95, £ 20.95$
}

Ant expert and photographer Mark Moffett likes to explore. In Adventures Among Ants, he describes his tropical encounters with his favourite kind of ant - the marauding type that forages as a huge stream, collecting prey as it goes. He climbs trees full of stinging ants, sits out in torrential rain in the jungle and endures relentless mosquitoes. This book showcases the pay-off: the moment when Moffett's camera captures ants looking fantastic as they effortlessly accomplish the incredible.

Moffett's ants are always sleek, polished and doing something spectacular. When an editor of National Geographic magazine first saw his photos, Moffett relates, she wondered how he made the ants look so glamorous. Anyone who has ever tried to take a photo of an ant has to wonder the same thing. They are not cooperative subjects, and the warmer they are, the faster they move. If there is enough light to provide sufficient depth of field to see the whole ant in focus, it is probably so hot that the ant will dash out of range before one

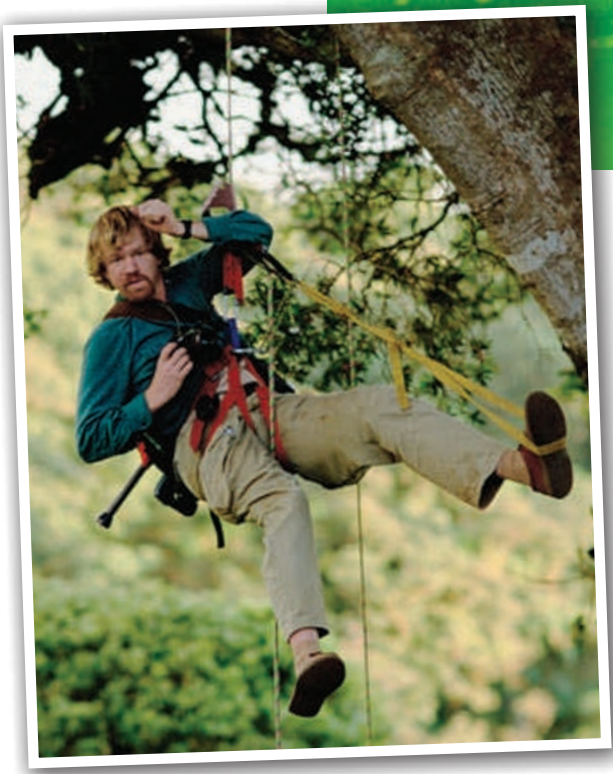

can click the shutter. Many years ago I attended an ant-photography workshop where Moffett proudly explained how to use three flashes to eliminate the tiny patch of light made by the reflection of a single flash on the ant's abdomen, which he found unattractive. The rest of us would struggle to get the ant in focus at all.

Moffett's close-ups convey an impression of calm and order. In one photo, neat rows of driver ants migrate to a new nest, each carrying a pupa. To the naked eye, eddies of ants merely

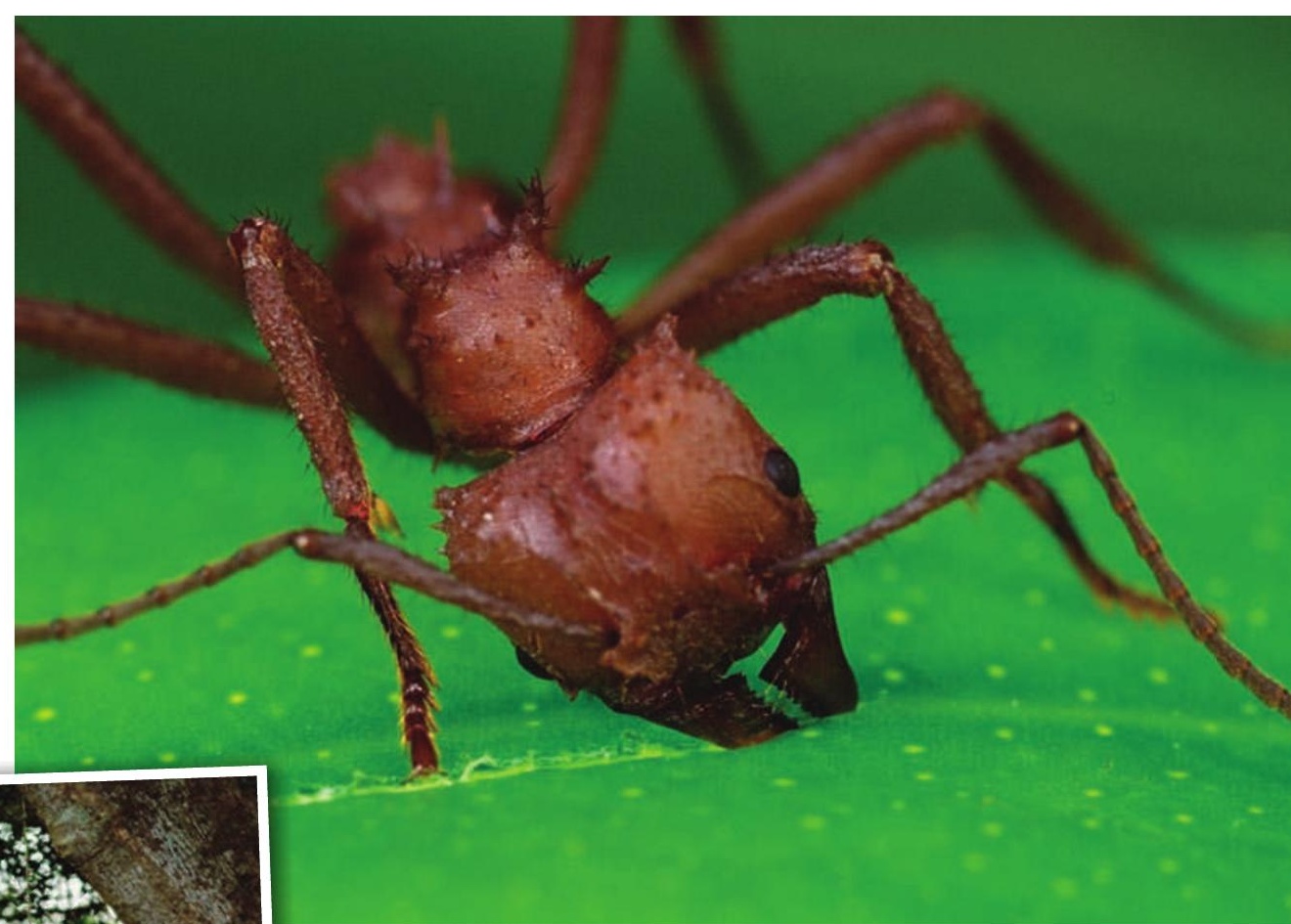

Photographer Mark Moffett (left) goes to great lengths to capture detailed images, such as this one of a leaf-cutter ant clipping leaf tissue.

form an inchoate wave. In another, tidy chains of weaver ants pull the edges of a leaf together to make their nest. As an 'exploding ant' dies alongside another that she has killed by rupturing her abdomen to douse the enemy with yellow goo, both seem to have achieved a Zen-like resignation to their fate. Even the marauder ants covering Moffett's sock in another photo look purposeful, intent on making their way to the top.

Moffett is driven by his admiration for the competence of individual ants. He writes mostly about how ant species differ in what each individual can do by itself, and what only a group can accomplish — just as a single person could grow his or her own food, but would have to work with others to construct a large building. However, unlike construction workers, individual ants do not assess what needs to be done or follow a blueprint. They respond to local cues, enabling ant colonies to accomplish tasks collectively.

It is hard to imagine how such emergent behaviour could be photographed on the closeup scale at which Moffett excels, and this may be why his accounts of collective behaviour in the text, as well as his photographs, tend to bypass the imperfect or stochastic. He writes that "in science we learn in bits and pieces, leaving others to unravel the details". The pieces he seeks involve individual achievements, rather than colony function; he wants to be the first to see a new ant escapade and capture it on film, not to test hypotheses. Adventures Among Ants offers exotic tales of places you will probably never go, and glimpses of beautiful ants performing marvellous feats.

Deborah M. Gordon is a behavioural ecologist in the Department of Biology at Stanford University, Stanford, California 94305-5020, USA, and author of Ant Encounters.

e-mail:dmgordon@stanford.edu 